\section{References}

1. Vaddineni SK, Taylor SM, Patterson MA, Jordan WD. Outcome after celiac artery coverage during endovascular thoracic aortic aneurysm repair: preliminary results. J Vasc Surg. 2007;45:467-471.

2. Waldenberger P, Bendix N, Petersen J, Tauscher T, Glodny B. Clinical outcome of endovascular therapeutic occlusion of celiac artery. J Vasc Surg. 2007;46:655-661.
3. Ishimaru S, Kawaguchi S, Koizumi N, Obitsu Y, Ishikawa M. Preliminary report on prediction of spinal cord ischemia in endovascular stent graft repair of thoracic aortic aneurysm by retrievable stent graft. J Thorac Cardiovasc Surg. 1998;115: 811-818.

\title{
False aneurysm with aortopulmonary shunt after replacement of the ascending aorta
}

\author{
Wilko Reents, MD, ${ }^{\mathrm{a}}$ Werner Kenn, MD, ${ }^{\mathrm{b}} \mathrm{Jörg}$ Babin-Ebell, MD, ${ }^{\mathrm{c}}$ Rainer G. Leyh, MD, PhD, and \\ Armin Gorski, MD, ${ }^{\text {a }}$ Würzburg and Bad Neustadt, Germany
}

The development of a false aneurysm with an aorto-pulmonary shunt is an extraordinary, uncommon, and lifethreatening condition. Surgical repair is inevitable, yet the operative approach is hampered by several pitfalls. This report describes the tailored surgical treatment of a mediastinal oseudoaneurysm with an aorto-pulmonary shunt arising after ascending aortic replacement.

\section{CLINICAL SUMMARY}

Five years after supracoronary replacement of the ascending aorta for acute aortic dissection, a 61-year-old woman had new-onset, rapidly progressive dyspnea. At presentation, she had orthopnea and peripheral edema. Auscultation revealed a continuous diastolic-systolic murmur and diminished basilar breath sounds. Chest radiography showed bilateral pleural effusions and interstitial fluid accumulation. Echocardiography demonstrated a moderate aortic valve insufficiency with prolapse of the right coronary cusp, a periaortic fluid accumulation, and the presence of a shunt between the ascending aorta and the pulmonary artery. Magnetic resonance imaging confirmed the presence of an aortopulmonary shunt (pulmonary/systemic perfusion ratio of 1.89) and demonstrated a large false aneurysm with extrav-

From the Departments of Cardiothoracic Surgery ${ }^{\mathrm{a}}$ and Radiology, ${ }^{\mathrm{b}}$ University Hospital Würzburg, Würzburg, Germany and the Department of Cardiovascular Surgery, Cardiovascular Clinic Bad Neustadt, ${ }^{\mathrm{c}}$ Bad Neustadt, Germany.

Disclosures: None.

Received for publication Sept 22, 2008; accepted for publication Nov 19, 2008; available ahead of print Feb 9, 2009.

Address for reprints: Wilko Reents, MD, Department of Cardiothoracic Surgery, University Hospital Würzburg, Oberdürrbacher Strasse 6, 97080 Würzburg, Germany. (E-mail: wilko.reents@herzchirurgie.de).

J Thorac Cardiovasc Surg 2010;139:e62-3 0022-5223/\$36.00

Copyright (C) 2010 Published by Elsevier Inc. on behalf of The American Association for Thoracic Surgery

doi:10.1016/j.jtcvs.2008.11.022 asation of contrast media at the level of the sinotubular junction (Figure 1).

Institution of cardiopulmonary bypass with cannulation of the right carotid artery and the femoral vein was performed before sternotomy. Systemic cooling was limited to a perfusion temperature of $28^{\circ} \mathrm{C}$. Resternotomy was uneventful, and the false aneurysm was covered with pericardium. Dehiscence of the suture line between the prosthesis and the noncoronary sinus had occurred, with visible aortic tissue necrosis and remnants of previously applied BioGlue (CryoLife Inc, Kennesaw, Ga). Additionally, there was a defect at the origin of the right pulmonary artery. The necrotic tissue was excised, and the defect in the pulmonary artery and aortic sinus was closed with bovine pericardium. The aortic valve showed degenerative changes and was replaced.

Pulmonary edema developed postoperatively. Fluid management and mechanical ventilation with positive endexpiratory pressure led to rapid recovery, and the patient was extubated 12 hours after the operation. The further postoperative course was uneventful, and the patient was discharged on the 10th postoperative day. There was no growth of bacteria or fungi from samples of the necrotic aortic tissue.

\section{DISCUSSION}

False aneurysm of the thoracic aorta is a rare event. Although development after trauma or infection has been described, previous surgery is the antecedent event in most cases. ${ }^{1}$ The incidence of pseudoaneurysm formation after cardiac surgery is not known but is estimated to be less than $0.5 \%{ }^{1}$ Sites of reduced resistance include previous anastomotic sites or incisions, where transmural disruption of the aortic wall is facilitated. Possible mechanisms include infection, technical shortcomings, and intrinsic disease of the aortic wall.

The operative management in this case had to overcome four principal challenges: (1) free rupture with 


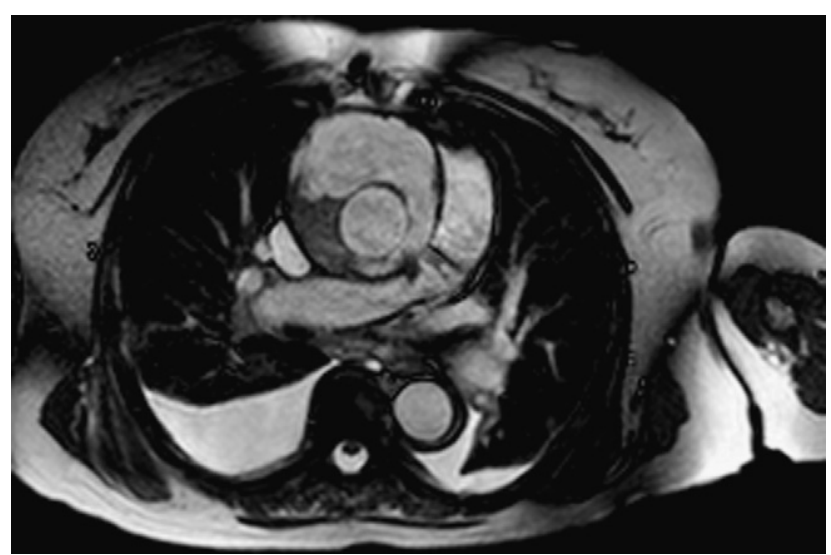

FIGURE 1. Magnetic resonance imaging scan showing periaortic false aneurysm and connection between false aneurysm and pulmonary artery.

exsanguination at resternotomy, (2) adequate cerebral perfusion in case of necessary circulatory arrest, (3) ventricular distention from aortic valve insufficiency, and (4) increased left-right shunt during cardiopulmonary bypass caused by the aortopulmonary fistula. In patients with previous surgery and a false aneurysm beneath the sternum, resternotomy in itself may precipitate fatal hemorrhage. Establishment of cardiopulmonary bypass before sternotomy is therefore mandatory. In one reported series, 4 of 10 patients undergoing surgery for mediastinal false aneurysm required circulatory arrest because of major bleeding during sternal reentry. ${ }^{2}$

In our patient, aortic valve regurgitation precluded simple hypothermic perfusion for possible circulatory arrest because of the high likelihood of temperature-induced ventricular fibrillation with subsequent ventricular distention. Alternative strategies may require left ventricular venting, either with a separate incision through the apex of the left ventricle or the left atrium or with the use of port-access techniques. ${ }^{3,4}$ The magnitude of left-right shunt is augmented during cardiopulmonary bypass. This could compromise systemic arterial blood flow and may lead to right ventricular distention in the presence of any pulmonary valve incompetence or temperature-induced ventricular fibrillation. Thus in our case preservation of cardiac contractility was essential, obviating the use of hypothermic perfusion. Selective antegrade cerebral perfusion eliminates the need for deep hypothermia during circulatory arrest. In our patient, cannulation of the carotid artery, but not the subclavian or femoral artery, enabled selective antegrade cerebral perfusion by proximal clamping of the carotid artery in case of a necessary circulatory arrest. Cerebral perfusion through the subclavian or the femoral artery requires clamping of the innominate artery or brachiocephalic trunk or the aorta, respectively. This would necessitate time-consuming and difficult preparation in case of bleeding from a ruptured false aneurysm. No attempt was made to close the aortopulmonary shunt before the establishment of cardiopulmonary bypass. Perfusion with cardiopulmonary bypass was uneventful, but the patient did have transient postoperative pulmonary edema. The increased fluid sequestration was presumable due to at least in part to pressure shifts during cardiopulmonary bypass. Shunt closure with a balloon occlusion catheter has been described as another potential strategy to control this problem. ${ }^{5}$

In summary, this case illustrates a tailored, individualized approach to the surgical management of a mediastinal pseudoaneurysm.

\section{References}

1. Atik FA, Navia JL, Svensson LG, Vega PR, Feng J, Brizzio ME, et al. Surgical treatment of pseudoaneurysm of the thoracic aorta. J Thorac Cardiovasc Surg. 2006;132:379-385.

2. Katsumata T, Moorjani N, Vaccari G, Westaby S. Mediastinal false aneurysm after thoracic aortic surgery. Ann Thorac Surg. 2000;70:547-552.

3. Byrne JG, Aklog L, Adams DH, Cohn LH, Aranki SF. Reoperative CABG using left thoracotomy: a tailored strategy. Ann Thorac Surg. 2001;71:196-200.

4. Petterson G, Nores M, Gillinov AM. Transfemoral control of ruptured aortic pseudoaneurysm at aortic root reoperation. Ann Thorac Surg. 2004;77:311-312.

5. Mukadam M, Barraclough J, Riley P, Bonser R. Acquired aorta-pulmonary fistula following proximal aortic surgery. Interact Cardiovasc Thorac Surg. 2005;4: 388-390. 